\title{
Effect of prazosin on diabetic nephropathy patients with positive $\alpha 1$-adrenergic receptor autoantibodies and refractory hypertension
}

\author{
LIN-SHUANG ZHAO ${ }^{1}$ and CHUN-YAN XU ${ }^{2}$ \\ ${ }^{1}$ Department of Endocrinology, Guangzhou Command Wuhan General Hospital, Wuhan, Hubei 430070; \\ ${ }^{2}$ Graduate College, Southern Medical University, Guangzhou, Guangdong 510515, P.R. China
}

Received January 15, 2014; Accepted June 20, 2014

DOI: $10.3892 /$ etm.2014.2036

\begin{abstract}
To investigate the effect of prazosin on patients with diabetic nephropathy (DN), $\alpha 1$-adrenergic receptor $(\alpha 1-\mathrm{R})$ autoantibodies and refractory hypertension, a total of 126 patients with DN and hypertension were recruited. The patients were divided into a refractory hypertension group, $(n=76)$ and a non-refractory hypertension group $(n=50)$. The epitope of the second extracellular loop of the $\alpha 1-\mathrm{R}$ (192-218) was synthesized and an enzyme-linked immunosorbent assay (ELISA) was performed to detect serum autoantibodies. In the group with DN-associated refractory hypertension, the positive rate of autoantibodies against the $\alpha 1-\mathrm{R}$ was $80.3 \%$ $(n=61)$. The 61 patients who were positive for $\alpha 1-R$ autoantibodies were randomly divided into a treatment group $(n=31)$ and a control group $(n=30)$. The patients were given drugs at the same dosage and administration, with the exception of prazosin, which was provided only to the patients in the treatment group [1 mg, three times a day (tid)] for a duration of six weeks. Subsequently, prazosin was added ( $1 \mathrm{mg}$, tid) to the therapeutic schedule of the patients in the control group and the $\alpha 1-\mathrm{R}$ autoantibody-negative group for another six weeks. The analysis was carried out on an intention-to-treat basis. The prazosin treatment resulted in significant improvements in hypertension in the treatment group $(\mathrm{P}<0.05)$, while there was no marked improvement in the control group. The total effective rate of hypertension improvement was $90.3 \%$ in the treatment group, which was higher compared with that of the control group (33.3\%). In conclusion, $\alpha 1-\mathrm{R}$ autoantibodies may play an important role in the pathogenesis of $\mathrm{DN}$ with refractory hypertension. Prazosin was demonstrated to be effective and safe in the treatment of DN with refractory hypertension.
\end{abstract}

Correspondence to: Professor Lin-Shuang Zhao, Department of Endocrinology, Guangzhou Command Wuhan General Hospital, 627 Wuluo Road, Wuhan, Hubei 430070, P.R. China

E-mail: zls7111@aliyun.com

Key words: prazosin, diabetic nephropathy with refractory hypertension, $\alpha 1$ adrenergic receptor, autoantibodies

\section{Introduction}

Diabetes mellitus (DM) has become a growing global public health issue. The morbidity rate is high and is expected to reach 435 million by 2030 (1). Diabetic nephropathy (DN) in particular is one of the most significant causes of mortality. DN-associated refractory hypertension is common and has a low treatment response rate. Therefore, methods of enhancing the treatment response rate of DN-associated refractory hypertension and reducing cardiovascular and cerebrovascular complications urgently require study. The pathogenesis of DN-associated refractory hypertension is very complicated (2); therefore, studies to increase understanding of the pathogenesis may assist in enhancing the treatment response rate, improving the lives of patients with $\mathrm{DN}$ and reducing the cardiovascular and cerebrovascular complications.

G protein-coupled-receptors (GPCRs), which include the $\alpha 1$-adrenergic receptor $(\alpha 1-\mathrm{R})$ and angiotensin II type 1 receptor (AT1 receptor), play important roles in the immunologic mechanism of cardio-cerebrovascular complications. They are a set of membrane surface glycoproteins coupled with guanine-binding regulatory proteins. Peptide bonds penetrate the cell membrane seven times, forming a structure where there are segments of the peptide inside and outside the cell with three peptide loops in each. The peptide loops outside the cell receive a signal stimulus, and transmit the extracellular signal to the inside of the cell. GPCR-mediated signals have roles in cardiovascular and visual regulation; they also participate in kidney function and regulate the immune response $(3,4)$. When GPCRs are repeatedly stimulated, autoantibodies are produced through an internal mechanism. The autoantibodies have a pathological activity similar to that of an agonist. Pathological effects are caused by interaction of the autoantibodies with the corresponding receptors, leading to autoimmune reactions and resulting in subsequent tissue damage (5-7).

Early studies revealed that the serum of patients with refractory hypertension and renal damage demonstrated a significantly increased positive rate of the AT1 receptor $(7,8)$. A subsequent study demonstrated that the efficacy of proteinuria reduction in patients with DN who were positive for AT1 receptor autoantibodies and treated with an AT1 receptor antagonist was significantly better than that in patients who tested negative for 
AT1 receptor autoantibodies; the efficacy differed significantly between patients with different autoantibody status when treated with the same medication (9). Therefore, it may be expected that morbidity due to DN is associated with these receptor autoantibodies. A study has revealed that AT1 receptor antibodies are able to increase the contraction rate of myocardial cells, raise the concentration of free calcium in vascular smooth muscle, and promote hypertension vascular reconstruction (10-12). However, further studies are required to investigate whether refractory hypertension is associated with the participation of $\alpha 1-\mathrm{R}$ autoantibodies and thus, whether the appliance of $\alpha 1-\mathrm{R}$ blockers may be effective in alleviating refractory hypertension.

Prazosin is an $\alpha 1-\mathrm{R}$ antagonist and may be competitively combined with $\alpha 1-\mathrm{R}$ autoantibodies. The function of prazosin is to selectively block the $\alpha 1-\mathrm{R}$ postsynaptic membrane of the vascular smooth muscle, relax small arteries and veins, and reduce peripheral resistance, thus lowering blood pressure (13). However, clinical observations have shown that an ideal effect is not achieved in all patients. For further observation, the present study used DN patients with refractory hypertension as subjects. Following testing for the presence of $\alpha 1-\mathrm{R}$ autoantibodies, targeted treatment with the $\alpha 1-\mathrm{R}$ blocker prazosin was applied to patients with DN and refractory hypertension who were positive for $\alpha 1-\mathrm{R}$ autoantibodies.

\section{Materials and methods}

Patients. A total of 126 patients with $\mathrm{DN}$ and $\geq$ level 2 hypertension from the Department of Endocrinology of the Guangzhou Command Wuhan General Hospital (Wuhan, China) were involved in in the current study. The present study was approved by the Human Subjects Committee of Guangzhou Command Wuhan General Hospital and the Southern Medical University. All the subjects gave their written informed consent. The mean \pm standard deviation (SD) systolic blood pressure (SBP)/diastolic blood pressure (DBP) was $176.1 \pm 11.3 / 105.4 \pm 9.7 \mathrm{mmHg}(1 \mathrm{mmHg}=0.133 \mathrm{kPa})$. Hypertension was diagnosed according to the 1999 'World Health Organization (WHO)/International Society of Hypertension (ISH) Hypertension Prevention Guide' (14). The antihypertensive drug treatment was applied based on the specific circumstances of the patients. The dose and types of drug were increased gradually [captopril 25-50 mg three times per day (tid), nitrendipine 10-20 mg once every $6 \mathrm{~h}$, hydrochlorothiazide 12.5-25 mg once per day, or furosemide 20-40 mg which was intermittently administered orally]. After three months, patients whose blood pressure remained $>140 / 90 \mathrm{mmHg}$ were assigned to the refractory hypertension group, and those whose blood pressure had been controlled by the drugs were placed in the non-refractory hypertension group. The diagnosis of DN was based on the five-phase standard proposed by Mogensen in 1989 (15). Patients with the following characteristics were excluded from the present study: i) other secondary kidney diseases; ii) participation in other clinical studies; iii) DN serum creatinine level $>131 \mu \mathrm{mol} / \mathrm{l}$; iv) DN hyperkalemia; and v) $\mathrm{SBP}>200 \mathrm{mmHg}$ or $\mathrm{DBP}>120 \mathrm{mmHg}$. Among the patients with DN who were involved in the present study, 76 had refractory hypertension (43 males and 33 females with a mean \pm SD age of $66.9 \pm 9.1$ years) and 50 had non-refractory hypertension (26 males and 24 females with an average age of $64.8 \pm 7.9$ years).
All drug applications, with the exception of insulin, were ceased in patients who were included in the current study. All clinical conditions and laboratory examination data were recorded. A 5-ml sample of fasting venous blood was collected from each patient. The plasma was obtained by centrifugation and stored at $-40^{\circ} \mathrm{C}$ for later use.

Solid phase peptide synthesis. An automatic peptide synthesizer (PSSM-8; Shimadzu, Kyoto, Japan) was used to synthesize peptide fragments targeting the epitopes of the second extracellular loop of $\alpha 1-\mathrm{R}$ (192-218; G-W-K-E-P-V -P-P-D-E-R-F-C-G-I-T-E-E-A-G-Q-A-V-F-S-S-V) (16). The purity of the synthetic peptides, analyzed by high performance liquid chromatography, was $>95 \%$.

Detection of autoantibodies by enzyme-linked immunosorbent assay (ELISA). The autoantibodies were detected according to a previous method (16). Blank, positive and negative controls were set up. The optical density (OD) of the blank control was set at zero in order to ensure the reliability of the results. Using serum from healthy individuals as a negative control and a reference point, the positive control was established with an OD two-fold higher than the reference OD. Testing positive for autoantibodies was defined as follows: OD value of the sample - OD value of the blank control/OD value of the negative control - OD value of the blank control $>2.1$.

Urinary albumin excretion rate (UAER) determination. Urine was collected for $24 \mathrm{~h}$ and benzoic acid was used for its preservation. The total volume was recorded and the 24-h urine protein level was determined by ELISA (Shanghai Baoman Biotechnology, Shanghai, China).

Methods of medication application and grouping. Patients with refractory hypertension who were positive for $\alpha 1-\mathrm{R}$ autoantibodies were randomly divided into the treatment group (group A) and control group (group B). Prazosin (1 mg tid) was administered to the treatment group only. The following medications were administered to the two groups: Captopril (25-50 mg tid), nitrendipine (10-20 mg once every $6 \mathrm{~h}$ ), hydrochlorothiazide (12.5-25 mg once per day) and enteric-coated aspirin (100 mg once per day). The antihypertensive efficacy of prazosin in groups A and B was compared. Following the first six weeks of the study, patients with refractory hypertension who tested negative (group C) and positive (group D) for $\alpha 1-\mathrm{R}$ autoantibodies were administered the same medication as group A. The antihypertensive efficacy of prazosin in groups $\mathrm{C}$ and $\mathrm{D}$ was compared.

Blood pressure observation. Blood pressure was measured twice per day (at 07:00 and 22:00) with a standard cuff and mercury sphygmomanometer, with the patients seated for 10 min prior to measurement. SBP and DBP were recorded. During the treatment period, patients were permitted to carry out normal daily activities and work, but prevented from doing intensive exercise.

Evaluation of the antihypertensive efficacy. Evaluation was based on the criteria for drug efficacy revised by the National Meeting of Cardiovascular Diseases in April 1979 (17): i) 
Table I. General clinical data characteristics of the patients with DN and hypertension.

\begin{tabular}{|c|c|c|c|c|c|c|c|c|c|}
\hline $\begin{array}{l}\text { Hypertension } \\
\text { group }\end{array}$ & $\mathrm{N}$ & $\begin{array}{l}\text { Gender } \\
(\mathrm{M} / \mathrm{F})\end{array}$ & $\begin{array}{c}\text { Age } \\
\text { (years) }\end{array}$ & $\begin{array}{l}\text { Course } \\
\text { (years) }\end{array}$ & $\begin{array}{l}\text { SBP/DBP } \\
(\mathrm{mmHg})\end{array}$ & $\begin{array}{c}\text { HR } \\
\text { (beats/min) }\end{array}$ & $\begin{array}{c}\text { BUN } \\
(\mathrm{mmol} / \mathrm{l})\end{array}$ & $\begin{array}{c}\mathrm{Cr} \\
(\mathrm{mmol} / \mathrm{l})\end{array}$ & $\begin{array}{c}\text { UAER } \\
(\mathrm{mmol} / \mathrm{l})\end{array}$ \\
\hline Refractory & 76 & $43 / 33$ & $66 \pm 9$ & $11 \pm 4$ & $176 \pm 11 / 101 \pm 7^{a}$ & $89 \pm 9$ & $9.9 \pm 1.2$ & $111.1 \pm 7.6$ & $317 \pm 29^{a}$ \\
\hline Non-refractory & 50 & $26 / 24$ & $5 \pm 11$ & $10 \pm 5$ & $142 \pm 15 / 88 \pm 9$ & $86 \pm 11$ & $8.9 \pm 1.6$ & $113.9 \pm 9.2$ & $206 \pm 31$ \\
\hline
\end{tabular}

DN, diabetic nephropathy; SBP, systolic blood pressure; DBP, diastolic blood pressure; HR, heart rate; BUN, blood urea nitrogen; Cr, serum creatinine; UAER, urinary albumin excretion rate. Data are presented as means \pm standard deviations. ${ }^{\text {a }}<0.05$ vs. the DN non-refractory hypertension group.

Table II. Comparison of test results for anti- $\alpha 1$ receptor autoantibodies in patients with DN and hypertension.

\begin{tabular}{|c|c|c|c|c|c|}
\hline $\begin{array}{l}\text { Hypertension } \\
\text { group }\end{array}$ & $\mathrm{N}$ & $\begin{array}{c}\alpha 1 \text {-receptor } \\
\text { positive cases }\end{array}$ & $\begin{array}{l}\text { Positive } \\
\text { rate }(\%)\end{array}$ & $\begin{array}{c}\alpha 1 \text {-receptor } \\
\text { negative cases }\end{array}$ & $\begin{array}{c}\text { Negative } \\
\text { rate }(\%)\end{array}$ \\
\hline Refractory & 76 & $61^{\mathrm{a}}$ & $80.3^{\mathrm{a}}$ & $15^{\mathrm{a}}$ & $19.7^{\mathrm{a}}$ \\
\hline Non-refractory & 50 & 6 & 12.0 & 44 & 88.0 \\
\hline
\end{tabular}

$\mathrm{DN}$, diabetic nephropathy. ${ }^{\mathrm{a}}<0.01 \mathrm{vs}$. the $\mathrm{DN}$ non-refractory hypertension group.

markedly effective: DBP is lowered by $\geq 10 \mathrm{mmHg}(1.33 \mathrm{kPa})$ and SBP is decreased to normal or by $>20 \mathrm{mmHg}(2.67 \mathrm{kPa})$; ii) effective: although the DBP is lowered $<10 \mathrm{mmHg}$, the SBP reaches normal levels. In the case of hypertension during the systolic period, a $>30 \mathrm{mmHg}(4 \mathrm{kPa})$ reduction of $\mathrm{SBP}$ is considered effective; iii) not effective: the reduction in blood pressure does not reach the above standard.

Statistical analysis. The data are presented as mean \pm SD and were processed using SPSS software, version 10.0 (SPSS, Inc., Chicago, IL, USA). The independent samples t-test was used to analyze the measurement data and the $\chi^{2}$ test was used for the enumeration data. $\mathrm{P}<0.05$ was considered to indicate a statistically significant difference.

\section{Results}

General clinical data characteristics. Statistically significant differences were observed only in the blood pressure and UAER between the DN patients with and without refractory hypertension $(\mathrm{P}<0.05$; Table I).

Comparison of $\alpha 1-R$ autoantibodies between the DN refractory and non-refractory hypertension groups. The number of positive cases and rate of the $\alpha 1-\mathrm{R}$ in the $\mathrm{DN}$ refractory hypertension group were significantly higher than those in the DN non-refractory group $(\mathrm{P}<0.01)$. This suggests that $\mathrm{DN}$ refractory hypertension may be associated with the pathogenic involvement of $\alpha 1-\mathrm{R}$ autoantibodies (Table II).

Comparison of the antihypertensive efficacy between the treatment and control groups of patients with DN, refractory hypertension and a positive anti- $\alpha 1-R$ status (groups $A$ and B). The blood pressure of group A dropped markedly following one week of treatment and decreased to $132 \pm 5 / 81 \pm 5 \mathrm{mmHg}$ after two weeks. Reexamination following six weeks of treatment revealed a further reduction to $129 \pm 5 / 78 \pm 4 \mathrm{mmHg}$. However, group B experienced no improvement in blood pressure following one, two and six weeks of treatment. The comparison of the two groups revealed statistically significant differences between the blood pressure measurements $(\mathrm{P}<0.05$ at one and two weeks and $\mathrm{P}<0.01$ at six weeks; Table III). The results indicate that prazosin is markedly effective as an antihypertension treatment for refractory hypertension.

General evaluation of the clinical antihypertensive efficacy between the treatment and control groups with DN, refractory hypertension and a positive anti- $\alpha 1-R$ antibody status (groups $A$ and $B$ ). The efficacy in the treatment group was significantly more improved than that in the control group. The difference between the two groups was statistically significant $(\mathrm{P}<0.05$; Table IV).

Comparison of the antihypertensive efficacy of prazosin between patients with negative and positive al-receptor autoantibody status in the DN refractory hypertension groups (groups $C$ and $D$ ). Following the administration of prazosin for one week, a significant improvement in blood pressure was observed in group D. Two weeks of continuous application lowered the blood pressure to $133 \pm 5 / 79 \pm 5 \mathrm{mmHg}$, and after six weeks, it was decreased to $123 \pm 7 / 77 \pm 3 \mathrm{mmHg}$. However, there was no notable improvement in group $\mathrm{C}$ following one week of treatment, and measurements at two and six weeks following treatment revealed that the blood pressure was not controlled within the normal range. The differences in blood pressure between the two groups were statistically significant $(\mathrm{P}<0.05$ at one and two weeks and $\mathrm{P}<0.01$ at six weeks; Table V).

Clinical observation of the side-effects of prazosin. In the group of 31 patients with DN and refractory hypertension that 
Table III. Comparison of anti-hypertensive efficacies between the treatment and control groups.

\begin{tabular}{|c|c|c|c|c|c|}
\hline \multirow[b]{2}{*}{ Group } & \multirow[b]{2}{*}{$\mathrm{N}$} & \multicolumn{4}{|c|}{ SBP/DBP (mmHg) } \\
\hline & & $\begin{array}{l}\text { Prior to } \\
\text { treatment }\end{array}$ & $\begin{array}{c}1 \text { week } \\
\text { after treatment }\end{array}$ & $\begin{array}{c}2 \text { weeks } \\
\text { after treatment }\end{array}$ & $\begin{array}{c}6 \text { weeks } \\
\text { after treatment }\end{array}$ \\
\hline Treatment & 31 & $176 \pm 11 / 101 \pm 7$ & $151 \pm 6 / 91 \pm 5^{a}$ & $132 \pm 5 / 81 \pm 5^{\mathrm{a}}$ & $129 \pm 5 / 78 \pm 4^{b}$ \\
\hline Control & 30 & $175 \pm 12 / 105 \pm 5$ & $171 \pm 10 / 99 \pm 5$ & $169 \pm 5 / 91 \pm 5$ & $161 \pm 5 / 90 \pm 5$ \\
\hline
\end{tabular}

SBP, systolic blood pressure; DBP, diastolic blood pressure. ${ }^{\mathrm{a}} \mathrm{P}<0.05,{ }^{\mathrm{b}} \mathrm{P}<0.01$ vs. the control group.

Table IV. Comparison of clinical effectiveness between the treatment and control groups.

\begin{tabular}{|c|c|c|c|c|c|}
\hline Group & $\mathrm{N}$ & $\begin{array}{c}\text { Not } \\
\text { effective, n }(\%)\end{array}$ & Effective, n (\%) & $\begin{array}{c}\text { Markedly } \\
\text { effective, n (\%) }\end{array}$ & $\begin{array}{c}\text { General effectiveness } \\
\text { rate, } \%\end{array}$ \\
\hline Treatment & 31 & $3(9.7)^{\mathrm{b}}$ & $7(22.6)^{\mathrm{a}}$ & $21(67.7)^{\mathrm{b}}$ & $90.3^{\mathrm{b}}$ \\
\hline Control & 30 & $20(66.7)$ & $4(13.3)$ & $6(20.0)$ & 33.3 \\
\hline$\chi^{2}$-value & & 21.339 & 9.258 & 19.331 & 31.627 \\
\hline P-value & & 0.0023 & 0.039 & 0.00269 & 0.0005 \\
\hline
\end{tabular}

${ }^{\mathrm{a}} \mathrm{P}<0.05,{ }^{\mathrm{b}} \mathrm{P}<0.01$ vs. the control group.

Table V. Comparison of the antihypertensive efficacy of prazosin between the $\alpha 1$-adrenergic receptor autoantibody negative and positive groups of patients with DN-associated refractory hypertension.

\begin{tabular}{|c|c|c|c|c|c|}
\hline \multirow[b]{2}{*}{ Group } & \multirow[b]{2}{*}{$\mathrm{N}$} & \multicolumn{4}{|c|}{$\mathrm{SBP} / \mathrm{DBP}(\mathrm{mmHg})$} \\
\hline & & $\begin{array}{l}\text { Prior to } \\
\text { treatment }\end{array}$ & $\begin{array}{c}1 \text { week } \\
\text { after treatment }\end{array}$ & $\begin{array}{c}2 \text { weeks } \\
\text { after treatment }\end{array}$ & $\begin{array}{c}6 \text { weeks } \\
\text { after treatment }\end{array}$ \\
\hline Negative & 15 & $163 \pm 7 / 101 \pm 5$ & $160 \pm 7 / 97 \pm 4$ & $169 \pm 5 / 91 \pm 5$ & $159 \pm 5 / 90 \pm 4$ \\
\hline Positive & 30 & $161 \pm 9 / 100 \pm 6$ & $147 \pm 5 / 93 \pm 5^{\mathrm{a}}$ & $133 \pm 5 / 79 \pm 4^{\mathrm{a}}$ & $123 \pm 5 / 77 \pm 3^{b}$ \\
\hline
\end{tabular}

DN, diabetic nephropathy; SBP, systolic blood pressure; $\mathrm{DBP}$, diastolic blood pressure. ${ }^{\mathrm{a}} \mathrm{P}<0.05,{ }^{\mathrm{b}} \mathrm{P}<0.01$ vs. the negative group. Data are presented as means \pm standard deviations.

was treated with prazosin for 12 weeks (group A), one patient had orthostatic hypotension, which was associated with a poor diet, and one patient had itchy skin. Upon applying calamine lotion, the itchiness disappeared and prazosin application was continued. In the same group, two male cases experienced occasional difficulty in urinating as a result of combined prostatic hyperplasia. Following the application of prazosin, urination improved. No palpitations or dizziness were observed.

\section{Discussion}

GPCRs are a group of membrane surface glycoproteins that combine with guanylate to regulate protein coupling. The $\alpha 1-\mathrm{R}$ receptor belongs to the GPCR family (18). The GPCR structure is regular in form and the ligands have a high specificity to their receptors (19). This specificity forms the foundation for the regulation of cell signaling and also presents a target for drug treatment (20). Receptor blockers are used to interfere with the receptors in order to block pathological effects $(21,22)$ and are therefore important in the protection of target organs.

The results of the present study revealed that of the 126 patients with DN hypertension, 76 were refractory which was a significant majority of the patients; the remaining 50 were non-refractory. The UAER of the refractory patients was notably higher than that of the non-refractory patients. The difference between the two groups was statistically significant. To further analyze the cause of the DN-associated refractory hypertension, the pathogenic mechanisms at the receptor level were studied. Firstly, a serum test of $\alpha 1-\mathrm{R}$ autoantibodies was conducted for all patients in the study. The $\alpha 1-\mathrm{R}$ autoantibody positive rate of $80.3 \%$ (61/76) in the group with DN refractory hypertension was significantly higher than the positive rate of $12.0 \%(6 / 50)$ in the group with non-refractory hypertension $(\mathrm{P}<0.01)$. This suggests 
that DN refractory hypertension may be associated with the pathogenic involvement of this receptor, and that the stimulating function of the anti- $\alpha 1-\mathrm{R}$ autoantibodies may play a role in the pathogenesis of hypertension. It has been reported that anti- $\alpha 1-\mathrm{R}$ autoantibodies exist in the serum of patients with malignant hypertension. These autoantibodies may also be obtained from rats immunized by synthetic polypeptides targeting the extracellular second loop of $\alpha 1-\mathrm{R}$ (192-218 amino acid residues) (23). Furthermore, Iwata et al have demonstrated that a dose-dependent positive chronotropic effect on the myocardial cells of newborn mice and activity similar to that of a receptor agonist may be blocked by the $\alpha 1-\mathrm{R}$ antagonist prazosin (24). The involvement of anti- $\alpha 1-\mathrm{R}$ autoantibodies in the pathogenic process of hypertension may be one of the main causes of refractory hypertension. A study by $\mathrm{Fu}$ et al investigated $\alpha 1-\mathrm{R}$ autoantibodies in patients with malignant hypertension (25). Consistent with the results of the current study, Fu et al observed that the binding of the antibody and its receptor may produce an effect similar to that of a receptor agonist. This may play a significant role in the pathogenesis of hypertension and its complications.

To further investigate the clinical antihypertensive efficacy, a subgroup analysis was carried out on the 61 cases with DN-associated refractory hypertension who tested positive for $\alpha 1-R$ autoantibodies. Prazosin was initially only applied to the treatment group, resulting in a significantly higher antihypertensive efficacy in the treatment group compared with that in the control group. Notably, clinical evaluation of the patients with DN-associated refractory hypertension who tested positive for anti- $\alpha 1-\mathrm{R}$ antibodies revealed that the general efficacy rate in the prazosin treatment group was $90.3 \%$ compared with $33.3 \%$ in the control group, taking into account statistical differences.

In order to analyze the difference in the efficacy of prazosin between the positive and negative $\alpha 1-\mathrm{R}$ autoantibody groups, the same drug treatment was applied to the two groups. The results demonstrated that the efficacy was higher in the $\alpha 1-\mathrm{R}$ autoantibody-positive group, thus supporting the hypothesis that antihypertensive efficacy differs between patients who are positive for $\alpha 1-\mathrm{R}$ antibodies and those who are negative, and providing an explanation as to why the same treatment may result in differing levels of efficacy. For example, with the same clinical drug application, the antihypertensive efficacy may be ideal for some patients but not for others. As a consequence, the targeting of therapy according to the individual situation of a patient may prevent the wasting of medical resources, misjudgment of the timing for treatment and avoid harm to organs caused by a continuously low treatment response rate. Analyzing the pathogenic mechanisms at the receptor level and then targeting the treatment according to the specific situation of the patient may be one of the key measures for enhancing the response rate to antihypertensive treatment.

The pathogenic mechanisms of hypertension are extremely complicated $(26,27)$ and include: insulin resistance, renal sodium and water retention, and the activation of the sympathetic nervous system and the renin angiotensin aldosterone system (RAAS). It is often difficult to control blood pressure to a level that complies with the standard required, especially in elderly patients with DN-associated hypertension. Long-term hypertension may result in systemic small vessel disease, the proliferation and fibrosis of the medial smooth muscle cells of small arteries, and the thickening and narrowing of the vascular walls, causing blood shortages and subsequent damage to important target organs, including the heart, brain and kidney tissues (28). Therefore, the aim of the present study was to aid the selection of appropriate antihypertensive drugs and provide solutions to the current challenges faced by clinical doctors. However, due to the intricacy of the pathogenic mechanisms of hypertension, further study is required.

The mechanism of action of prazosin is the selective blocking of the postsynaptic membrane $\alpha 1-\mathrm{R}$ of the vascular smooth muscle, the relaxation of small arteries and veins, and the reduction of peripheral resistance. There may be a slight increase in cardiac output. Long-term application of prazosin may improve lipid metabolism, lower total cholesterol, triglycerides and low-density lipoprotein cholesterol levels, and raise high-density lipoprotein cholesterol levels, with a positive effect on glucose metabolism (29). It may also reduce the difficulties in urination faced by elderly people due to prostatic hyperplasia (30). The $\alpha 1-\mathrm{R}$ blocker prazosin may also safely and effectively lower blood pressure; however, for elderly patients, orthostatic hypotension should be prevented. Prazosin treatment is also advantageous to patients with dyslipidemia or an abnormal glucose metabolism.

In conclusion, detecting $\alpha 1-\mathrm{R}$ autoantibodies in the serum, considering the pathogenic mechanism at the receptor level and applying target treatment with a receptor antagonist accordingly for patients with DN-associated refractory hypertension is of clinical significance for enhancing the antihypertension treatment response rate.

\section{Acknowledgements}

This study was supported by the Natural Science Fund Project of Hubei Province (No. 2011CHC001).

\section{References}

1. Tabák AG, Herder C, Rathmann W, Brunner EJ and Kivimäki M: Prediabetes: A high-risk state for developing diabetes. Lancet 379: 2279-2290, 2012.

2. Weir MR: Salt, hypertension, and proteinuria in diabetic nephropathy. Lancet Diabetes Endocrinol 2: 351-352, 2014.

3. Dragun D, Philippe A, Catar R and Hegner B: Autoimmune mediated G-protein receptor activation in cardiovascular and renal pathologies. Thromb Haemost 101:643-648, 2009.

4. Smith SO: Structure and Activation of the Visual Pigment Rhodopsin. Ann Rev Biophys 39: 309-328, 2010.

5. Hilme E, Hansson L, Sanberg L, Söderström T and Herlitz H: Abnormal immune function in malignant hypertension. J hyper tens 11: 989 -994, 1993.

6. Dragun D, Philippe A, Catar R and Hegner B: Autoimmune mediated G-protein receptor activation in cardiovascular and renal pathologies. Thromb Haemost 101: 643-648, 2009.

7. Sun YX, Zhu F, Wang M, Li ZZ and Liao YH. Increased autoantibody production against AT(1)-receptors and alpha(1)-adrenergic receptors in hypertensive patients. Zhonghua Xin Xue Guan Bing Za Zhi 36: 16-19, 2008 (In Chinese).

8. Zhao LS, Xiang GD, Yue L, Liao YH, Zhou ZH and Sun HL: Clinical effects of valsartan treatment on refractory hypertension with the positive autoantibody of AT1 receptor in diabetes mellitus patients. Chin J Diabetes 16: 607-610, 2008 (In Chinese)

9. Zhao LS, Bai WW, Xiang GD, Yue L and Sun HL. Clinical evaluation of valsartan and metoprolol tartrate in treatment of diabetic nephropathy with positive beta1-adrenergic and antiangiotensin II type 1 receptor antibody. Chin Med J (Engl) 125: 3543-3547, 2012 . 
10. Qiu Y, Zhu F, Liao YH, Li ZZ and Wang M. Association between positive autoantibodies against AT1-receptor and cardiac remodeling in patients with hypertension. Zhonghua Xin Xue Guan Bing Za Zhi 35: 1141-1144, 2007.

11. Zhu F, Sun YX, Liao YH, Wei YM, Chen M, Wang M and Zhou ZH. Agonistic AT(1) receptor autoantibody increases in serum of patients with refractory hypertension and improves $\mathrm{Ca}(2+)$ mobilization in cultured rat vascular smooth muscle cells Cell Mol Immunol 5: 209-217, 2008.

12. Li LD, Tian M, Liao YH, Zhou ZH, Wei F, Zhu F, Wang M, Wang B and Wei YM. Effect of active immunization against angiotensin II type 1 (AT1) receptor on hypertension \& arterial remodelling in spontaneously hypertensive rats (SHR). Indian J Med Res 139: 619-624, 2014

13. Wangensteen R, O'Valle F, Del MR, Vargas F and Osuna A Chronic alpha1-adrenergic blockade improves hypertension and renal injury in L-NAME and low-renin L-NAME-DOCA hypertensive rats. Med Sci Monit 8: 378-384, 2002.

14. Chalmers J: The 1999 WHO-ISH Guidelines for the Management of Hypertension. Med J Australia 171: 458, 1999.

15. Mogensen MM, Tucker JB and Stebbings H: Microtubule polarities indicate that nucleation and capture of microtubules occurs at cell surfaces in Drosophila. J Cell Biol 108: 1445-1452, 1989.

16. Liao YH, Wei YM, Wang M, Wang ZH, Yuan HT and Cheng LX Autoantibodies against AT1 receptor and $\alpha 1$ adrenergic receptor in patients with hypertension. Hypertens Res 25: 641-646, 2002.

17. Writing group of 2010 Chinese guidelines for the management of hypertension. 2010 Chinese guidelines for the management of hypertension. Chin J Hypertens 19: 701-743, 2011.

18. Wallukat G and Schimke I. Agonistic autoantibodies directed against G-protein-coupled receptors and their relationship to cardiovascular diseases. Semin Immunopathol 36: 351-363, 2014

19. Shi L and Javitch JA. The binding site of aminergic G proteincoupled receptors: the transmembrane segments and second extracellular loop. Annu Rev Pharmacol Toxicol 42: 437-467, 2002.
20. Piali L and Richardson DR. G-protein coupled receptors: drug targets of key importance. Curr Top Med Chem 11: 608, 2011.

21. Thomas GN, Chan P and Tomlinson B. The role of angiotensin II type 1 receptor antagonists in elderly patients with hypertension. Drug Aging 23: 131-155, 2006.

22. Randle LE, Sathish JG, Kitteringham NR, Macdonald I, Williams DP and Park BK. alpha(1)-Adrenoceptor antagonists prevent paracetamol-induced hepatotoxicity in mice. Br J Pharmacol 153: 820-830, 2008.

23. Zhou ZH, Qi Q, Liao YH, Wang B, Li LD, Wei F, Wang M and Wei YM. Preparation of the antibodies against alpha 1-adrenergic receptor with exciting actions. Chinese J Clin Rehabil 10: 51-54, 2006 (In Chinese).

24. Iwata M, Yoshikawa T, Baba A, Anzai T, Nakamura I, Wainai Y, Takahashi $\mathrm{T}$ and Ogawa $\mathrm{S}$. Autoimmunity against the second extracellular loop of beta(1)-adrenergic receptors induces betaadrenergic receptor desensitization and myocardial hypertrophy in vivo. Circ Res 88: 578-586, 2001.

25. Fu ML, Herlitz H, Schulze W, et al: Autoantibodies against the angiotensin receptor (AT1) in patients with hypertension. J Hypertens 18: 945-953, 2000.

26. Ogihara T, Asano T, Ando K, et al: Angiotensin II-induced insulin resistance is associated with enhanced insulin signaling. Hypertension 40: 872-879, 2002.

27. Touyz RM and Schiffrin EL: Signal transduction mechanisms mediating the physiological and pathophysiological actions of angiotensin II in vascular smooth muscle cells. Pharmacol Rev 52: 639-672, 2000.

28. Dzielak DJ: Immune mechanisms in experimental and essential hypertension. Am J Physiol 260: R459-R467, 1991.

29. Shen KP, Lin HL, Hsieh SL, Kwan AL, Chen IJ and Wu BN. Eugenosedin-A prevents hyperglycaemia, hyperlipidaemia and lipid peroxidation in C57BL/6J mice fed a high-fat diet. J Pharm Pharmacol 61: 517-525, 2009.

30. Liao CH, Guh JH, Chueh SC, et al. Anti-angiogenic effects and mechanism of prazosin. Prostate 71: 976-984, 2011. 